An ESRC Research Group

\title{
Development and social capital
}

\author{
GPRG-WPS-007
}

\author{
Marcel Fafchamps
}

\section{Global Poverty Research Group}

Website: http://www.gprg.org/

The support of the Economic and Social Research Council (ESRC) is gratefully acknowledged. The work was part of the programme of the ESRC Global Poverty Research Group. 


\title{
GPRG-WPS-007
}

\section{Development and Social Capital}

\author{
Marcel Fafchamps \\ University of Oxford *
}

\begin{abstract}
This paper examines social capital and its relation with economic development. We focus on the role that interpersonal relationships play in social exchange, whether through the market or through the provision of public goods. By facilitating search and trust, social capital can increase the efficiency of social exchange when formal institutions are weak. But the benefits from social capital are likely to be unequally distributed. Given these features, documenting empirically the benefits of social capital is complicated by the presence of negative and positive externalities and by the existence of leadership and group effects. Lessons for development policy are drawn at the end.
\end{abstract}

\section{Introduction}

The purpose of this paper is to reflect, from an economist's point of view, on the methodological issues raised by the study of social capital. This term has been used in many different ways to cover a broad range of phenomena (e.g. Dasgupta \& Serageldin 2000, Grootaert \& van Bastelaer 2002a, Durlauf \& Fafchamps 2005). Perhaps it is best seen as a way of federating research programs in various social sciences (Woolcock \& Narayan 2000). If so, the quest for an allencompassing definition may be futile or even counter-productive, because different disciplines

\footnotetext{
${ }^{*}$ Department of Economics, University of Oxford, Manor Road, Oxford OX1 3UQ. Email: marcel.fafchamps@economics.ox.ac.uk. Fax: +44(0)1865-281447. Tel: +44(0)1865-281446.
}

The support of the Economic and Social Research Council (ESRC) is gratefully acknowledged. The work was part of the programme of the ESRC Global Poverty Research Group. 
need to appropriate the term differently depending on how it fits in their paradigm. What is important is that the phrase social capital facilitates the exchange of ideas across disciplines.

Human societies are complex combinations of individuals, institutions, and networks of personal relationships. Up to now, economists have focused primarily on individuals and institutions (e.g., markets, firms, governments, households). For a long time they did well by ignoring the middle ground, the networks of personal relationships that oil the system and bring it to life. These personal relationships are important because they are the locale where human emotions are realized. While economists can deal with subjective beliefs and with a wide range individual preferences (including addiction, criminal tendencies, thirst for power, etc), their models are not equipped to accommodate human emotions such as trust, anger, and spite - especially when these emotions are directed at specific individuals. It is not that these emotions have been entirely ignored by economists (e.g. Akerlof \& Kranton 2000, Becker 1968, Barr 2002b, Barr 2002c), but they often violate the assumption of rationality and thus do not fit into the paradigm. This remains largely true to this day.

In my view, economists' reluctance to delve into the world of emotions is because they intuitively realize the possible consequences. They understand the usefulness of understanding emotions for positive work - as illustrated for instance in experimental work on shame and guilt (e.g. Barr 2002b, Barr 2002a). But they fear the repercussions on their normative work. Economics concerns itself with government policy and firm behavior. By assuming that people are rational and cold-headed, economists propose policies that are organized around financial incentives. Individuals then respond to these incentives of their own free will. Focusing on emotions for policy design would produce a very different kind of policy instruments such as propaganda (for governments) and advertising (for firms). As a rule, economists see these as ways of manipulating the public by deceiving them and playing with their emotions - even if it is 
for a 'good cause'. Anyone who worries about the use fascist and communist governments made of propaganda should perhaps be grateful that economics, as a science, has resisted focusing on emotions and human irrationality.

Leaving emotions aside, there remains the issue of networks. Up to recently, the economist's toolbox was not powerful enough to deal with the complexity brought by networks. This, however, is slowly changing, with much new theoretical work on networks (e.g. Kranton \& Minehart 2001, Bala \& Goyal 2000). It is likely that, over the next few years, economic theory will move further into the study of networks. This should lay the foundations for a detailed economic research agenda focusing on social capital.

Empirical work on social capital by economists has already begun, without necessarily waiting for a detailed theoretical framework (e.g. Keefer \& Knack 1997, Narayan \& Pritchett 1999, Fafchamps \& Minten 2002). The World Bank has been particularly active in encouraging multidisciplinary research on social capital cit (e.g. Grootaert \& van Bastelaer 2002b, Woolcock \& Narayan 2000, Bebbington, Guggenheim, Olson \& Woolcock 2004). This effort is best illustrated by the two volumes on the subject edited by Dasgupta \& Serageldin (2000) and by Grootaert \& van Bastelaer (2002a). The purpose of this paper less ambitious. Our aim is to raise a number of issues relative to empirical work on social capital, with a particular emphasis on equity and development. We first discuss a number of conceptual issues, seeking to clarify some of the confusion surrounding work on social capital. We then draw lessons for empirical work.

\section{Conceptual framework}

To organize the discussion, we focus on the role that interpersonal relationships and social networks play in the efficiency of social exchange. By social exchange, we mean any form of human exchange, whether material or immaterial, economic or social. The exchange of goods 
for money - i.e., the market - falls under this definition. So does the provision of public goods, which can be seen as the outcome of a joint production process.

As Hayek (1945) was the first to point out, information asymmetries are an inescapable feature of human society. As a result, exchange is hindered either because agents who could benefit from trade cannot find each other, or because, having found each other, they do not trust each other enough to trade. In either case, mutually beneficial exchange does not take place. Similar principles apply to the provision of public goods. Search and trust are thus two fundamental determinants of the efficiency of social exchange. If we can finds ways of facilitating search and of fostering trust, we can improve social exchange.

There are basically two ways of achieving this dual objective: via formal institutions (e.g., stock exchange) or via interpersonal relationships (e.g., word-of-mouth). The literature on social capital focuses principally on the latter. In the following pages we illustrate how social capital can raise efficiency. We begin by examining the possible effects of social capital on search. We then turn to trust. Public goods are discussed in the following sub-section. The relationship between social capital and development is examined next. The last sub-section explores the relationship between social capital and equity.

\subsection{Social Capital and Search}

In order to illustrate the role of social capital in search, it is useful to compare US equity and labor markets. Thanks to the existence of a stock market, it is very easy for a seller of stock to find a buyer at the market clearing price. This is not the case in labor markets where there is no equivalent institution circulating accurate and up-to-date information about jobs and workers.

In his path-breaking study of the US labor market, Granovetter (1995) brought to light the role played by interpersonal relationships in channeling information about jobs and job 
applicants. A large proportion of jobs are allocated on the basis of personal recommendation and word-of-mouth. Fafchamps \& Minten (1999) provide evidence that agricultural traders often rely on personal relationships to obtain information about market conditions and to identify trade opportunities. These phenomena can be understood as an endogenous, spontaneous adaptation to the absence of a formal clearing house equivalent to the stock market.

As this comparison demonstrates, observing that social capital plays a role in markets does not, by itself, constitute evidence that social capital is necessary and should be nurtured. In economies with sufficient organization capacity, the development of formal institutions may be a superior alternative. This is not to say that formal institutions are always superior. Setting up a stock exchange or commodity exchange, for instance, facilitates trade. But it is an extremely costly endeavor and it restricts entry into brokerage since brokers have to put a very large bond and the space on the exchange floor is typically restricted. For many markets, investing in a formal exchange would not make economic sense. In these markets, reliance on informal networks is likely to be optimal. Intervention can then focus on fostering 'social capital', that is, on a smoother and more accurate dissemination of information through informal networks and business associations.

By changing the cost of setting up a formal institution, technological change can improve the cost-effectiveness of formal solutions to information sharing and coordination problems. A good illustration of this idea is the partial replacement of personal network-based exchange by anonymous internet-based exchange (e.g., Ebay) for goods such as collectibles or second-hand durables. Whether informal institutions are more efficient than formal institutions thus depends on the relative costs and benefits of each. While informal institutions typically generate smaller benefits because their reach is limited, they also cost less because they free-ride on other social activities - e.g., people exchanging information about job prospects while attending a wedding. 
Other things being equal, we expect the cost of formal institutions to fall with the organizational capacity of an economy - or part thereof. Consequently, we anticipate that technologies that improve organization capacity - such as telecommunication and information technology - may enable an economy to switch from informal to formal institutions for the purpose of solving information sharing and coordination problems, such as matching in thin markets.

\subsection{Social Capital, Trust, and Efficient Exchange}

As argued in Fafchamps (2002), trust can be understood as an optimistic expectation or belief regarding other agents' behavior. The origin of trust may vary. Sometimes, trust arises from repeated interpersonal interaction. Other times, it arises from general knowledge about the population of agents, the incentives they face, and the upbringing they have received (Platteau 1994). The former can be called personalized trust and the latter generalized trust. The main difference between the two is that, for each pair of newly matched agents, the former takes time and effort to establish while the latter is instantaneous.

In most situations, trusting others enables economic agents to operate more efficiently e.g., by invoicing for goods they have delivered or by agreeing to stop hostilities. Whenever this is the case, generalized trust yields more efficient outcomes than personalized trust. The reason is that, for any pair of agents, generalized trust is established faster and more cheaply than personal trust. This observation has long been made in the anthropological literature on generalized morality. Fostering generalized trust can thus potentially generate large efficiency gains. How this can be accomplished, however, is unclear.

Clubs and networks are different concepts having to do with the structure of links among economic agents. Clubs describe finite, closed groupings. Networks describe more complex situations in which individual agents are related only to some other agents, not all. The term 
'network' is sometimes used to describe the entire set of links among a finite collection of agents. Other times, it is used to describe the set of links around a specific individual. To avoid confusion, we call the second concept subjective network.

Among other things, clubs and networks can be used to describe the extent to which personalized and generalized trust exist in a population. Perfect generalized trust corresponds to the case where all agents belong to a single club (or complete network) and trust all other members. Situations in which generalized trust exists only among sub-populations (say, Jewish diamond dealers in New York - Bernstein (1992)) could be described as small clubs. Situations in which individual agents only trust is limited number of agents they know individually can be described as a network.

From the above discussion, it is immediately clear that, since trust is beneficial for economic efficiency, the loss from imperfect trust can be visualized as the difference between the actual trust network and the minimum network that would support all mutually beneficial trades. Following this reasoning, inefficiency is expected to be highest in societies where the trust network is very sparse (Granovetter 1995). Inefficiency will also be large when sub-groups who could trade with each other are unconnected to each other, even if many more links exist within each sub-group (e.g. Bloch, Genicot \& Ray 2004, Goyal, van der Leij \& Moraga-Gonzalez 2004).

Based on empirical work in a dozen of African countries, Fafchamps (2004) studies in detail the relationship between market efficiency and level of institutional development. From this work it appears that legal institutions play a minor role in African markets, except in some countries and among larger firms. The reason is that in a poor economy most market transactions are too small to justify court action and most people have no assets to foreclose upon. As a result, relational contracting dominates markets, especially in manufacturing. Social networks play a paramount role in circulating information and facilitating the formation of new exchange 
relationships. Similar processes are also present in developed economies, as shown for instance by the work of Bernstein (1992) and Bernstein (1996), although they probably play a less prominent role.

In a market environment dominated by relational contracting, formal institutions can broaden the scope for exchange in many different ways. Business registration and ID card allow contractual parties to be identified unambiguously - and thus to be traced in case of breach of contract. Grading, standards, and ISO certification facilitate quality assessment. Credit reference agencies circulate market information beyond the range of social networks, thereby facilitating screening. A free press (with safeguards against slandering and defamation) publicizes the most outrageous cases of opportunistic behavior. Labor exchange, temp agencies, and headhunting firms circulate information about job applicants. Organized exchanges (e.g., stock and commodity exchanges, foreign exchange auction) reduce the risk of contractual breach through various institutional mechanisms - e.g., externally audited accounts, posting of bond, internal scrutiny). As the above list illustrates, lawyers and courts are only part of the formal institutional infrastructure required for efficient market exchange. In practice, markets work best when formal institutions serve to expand the scope of social networks and to broaden the range of possible exchange. Although they may be impersonal, true markets are nearly never anonymous: the identity of the other party is nearly always essential, to the point that a brand or firm name has a value per se (Tadelis 1999). The only truly anonymous markets are the least developed ones, e.g., roadside vendors on streets and markets in the developing world.

\subsection{Social Capital and Public Goods}

In the preceding sub-section we discussed the role of trust in fostering exchange. Trust is also an essential ingredient in the delivery of public goods. In many cases, the state can organize 
the provision of public goods by taxing individuals. Whenever this is true, trust is not essential. But there are many forms of public goods that cannot be harnessed through state intervention.

In his work on PTA run schools, for instance, Coleman (1988) shows that parental involvement in school affairs has a beneficial external effect on student achievement, probably because it leads children to believe their parents care about their education. Parental involvement, in turn, requires trust to reduce and solve interpersonal conflicts and to minimize fears of free-riding. In this example, the externality is a public good that cannot be harnessed by state intervention. Voluntary participation by parents is essential.

In poor countries, there are many situations in which the state could, theoretically, intervene to provide a public good, but is unable to do so because its tax base and its capacity to organize are limited. Collective action can serve as substitute to the state. However, because it cannot rely on the coercive action of the state (e.g., the ability to tax and enforce contracts), collective action is much harder to set in motion. Two essential ingredients are then required: leadership and trust. A leader is required who is capable of convincing community members that they should voluntarily contribute to the public good. Trust is necessary to resolve conflicts among competing interests and to reduce fears of free-riding. Leaders can also help raise the level of trust in the community.

What the above discussion indicates is that delivering public goods via voluntary organizations depends critically on local trust and leadership. If these ingredients are absent, for instance after a civil war, outside intervention by the state or by development agencies may in some cases be faster than waiting for trust between communities to be rebuilt (e.g. Bigombe, Collier \& Sambanis 2000, Collier \& Hoeffler 2002). How successful this approach may be depends critically on the state of the infrastructure and means of communication needed for outside intervention. Furthermore, good local leaders are rare. Projects that work well in one place because 
of strong local involvement need not be replicable elsewhere if local leaders are weak. Pilot projects of public good delivery through local communities may provide wrong signals if their placement is correlated with the presence of good local leaders who managed to attract the pilot project to their community.

\subsection{Social Capital and Development}

In a well publicized book, Putnam, Leonardi \& Nanetti (1993) argue that Northern Italy developed faster than Southern Italy because the former was better endowed in social capital - measured as membership in groups and clubs. This book triggered a plethora of research purposing to show that social capital favors growth (Keefer \& Knack 1997).

In his latest book, however, Putnam himself undermines the very foundation of the new mantra he created. Focusing on the U.S. experience since the 1950's, Putnam shows that social capital, defined as membership in formal and informal clubs, has declined monotonically since the 1950s. This is true for all states, all decades, and all measures of social capital. Moreover, he finds no relationship between the speed of the decline and economic performance across U.S. states or across time periods. For instance, the 1990's were a period of rapid growth in the U.S. but also of rapid decline in social capital.

Putnam worries about the demise of social capital in the U.S. An alternative interpretation of his findings is that, because generalized trust has improved over the period studied, club membership has become less necessary. In contrast, the Italian experience related to an earlier period in which generalized trust was insufficient or incomplete and small clubs helped broaden the range of personalized trust.

This raises the possibility that clubs and networks are important at intermediate levels of development. Their function is to broaden the range and speed of social exchange beyond the 
confines of personalized trust. But once a sufficiently high level of generalized trust has been achieved, clubs and networks are no longer necessary and wither away (North 2001).

This is not the interpretation given by Putnam, who presents the rise in lawyers and lawsuits per capita as evidence that generalized trust has fallen. An increased reliance on lawyers and courts does not, by itself, constitute evidence against generalized trust, however. As Bigsten, Collier, Dercon, Fafchamps, Gauthier, Gunning, Isaksson, Oduro, Oostendorp, Patillo, Soderbom, Teal \& Zeufack (2000) and Fafchamps \& Minten (2001) have shown, when legal institutions are weak and generalized trust absent, economic agents are extremely careful in their dealings with people they do not know. As a result, breach of contract is fairly rare and when it occurs it is resolved through face-to-face negotiations. An improvement in legal institutions may induce economic agents to deal with people they do not know. The willingness to deal with strangers is precisely what we have called generalized trust. Because dealing with strangers is more risky, however, this normally leads to a rise in the absolute number of cases of breach which in turn results in more lawsuits. ${ }^{1}$

This can easily be illustrated with a simple example. Consider an economy with two types of borrowers: weak and bad, in proportions $1-\beta$ and $\beta$. Bad agents never repay. Weak agents repay if deterrence is high, and do not repay if it is low. When deterrence is low, nobody repays. Consequently lenders do not lend; there is market failure. When deterrence is high, lenders get repaid with probability $1-\beta$. They can also sue defaulting borrowers and recover a fraction

\footnotetext{
${ }^{1}$ This can easily be illustrated with a simple example. Consider an economy with two types of borrowers: weak and $\mathrm{bad}$, in proportions $1-\beta$ and $\beta$. Bad agents never repay. Weak agents repay if deterrence is high, and do not repay if it is low. When deterrence is low, nobody repays. Consequently lenders do not lend; there is market failure. When deterrence is high, lenders get repaid with probabiliy $1-\beta$. They can also sue defaulting borrowers and recover a fraction $\varepsilon>0$ of the principal.

Let the cost of funds be $r$. Competition between lenders sets the interest rate on loans $i$ such that

$$
\beta \varepsilon+(1-\beta)(1+i)=1+r
$$

In low deterrence state, there is no trade and no lawsuit; in the high deterrence state, there is trade and lawsuits on a proportion $\beta$ of all loans.
} 
$\varepsilon>0$ of the principal. Let the cost of funds be $r$. Competition between lenders sets the interest rate on loans $i$ such that

$$
\beta \varepsilon+(1-\beta)(1+i) \geq 1+r
$$

As long as $i$ satisfies (2.1), it is in the interest of lenders to lend. It follows that in the low deterrence state, there is no trade and no lawsuit while in the high deterrence state, there is trade and lawsuits on a proportion $\beta$ of all loans. Better contract enforcement institutions have raised generalized trust and trade while at the same time resulting in more default and lawsuits.

Using detailed survey data from the 1990's, Fafchamps (2004) compares contract enforcement among manufacturers in Ghana, Kenya and Zimbabwe. He finds that Zimbabwe has better courts than the other two countries and that Zimbabwean firms are more likely to deal with people they do not know. But Zimbabwe also has more breach. Because Zimbabwean firms know each other less, they are also less likely to resolve contractual disputes through negotiations and more likely to go to court. This empirical evidence illustrates that an increase in generalized trust can go hand in hand with an absolute rise in the incidence of breach and lawsuits.

A similar kind of reasoning can be followed for public goods. In undeveloped economies, the state is weak and under-funded. Consequently it cannot organize the delivery of all needed public goods. This is particularly true for local public goods or for public goods that require a modicum of voluntary involvement to limit free-riding (of which corruption is but one manifestation).

Social capital provides an alternative. This idea was first put forth by de Soto (1989) and recently revisited by Rose (2000b) and Rose (2000a) in his work on Russia. Clubs formed for non-economic purposes (e.g., religious worship, political parties) have leaders. In the absence of public good provision by the state, these leaders may decide to mobilize club members (e.g., the religious congregation) to provide missing public goods. History is replete with examples of churches and Islamic fraternities intervening to build schools and clinics and to provide a variety 
of public services. Here, sharing a common religious fervor is the basis for trust and the religious hierarchy provides the necessary leaders. Some large secular organizations have adopted similar practices - e.g., communist parties yesterday, international NGOs today.

These issues have an immediate effect on empirical work on social capital. The difficulty comes from the fact that first best can in principle be achieved without paying attention to clubs and networks. Generalized trust in commercial contracts, for instance, can theoretically be achieved via laws and courts. Thanks to taxation, public goods can in principle be organized by the state at lower cost in terms of public mobilization and leadership skills. As North (1973) has argued, the rise of the western world is precisely due to the invention of institutions that protect property rights and make the state more effective at delivering public goods. Clubs, networks, and community-based voluntary organizations can improve efficiency in economic exchange and public good delivery. But they are second-best solutions. The first best approach is to get legal institutions and state organization in order.

Whether or not social capital raises efficiency therefore depends on the level of institutional development. Suppose that laws and courts are insufficient to ensure respect of commercial contracts. This situation can arise anywhere (Bernstein 1996) but it is probably most severe in poor countries where many transactions are small and buyers and sellers are too poor for court action to yield reparation (e.g. Bigsten et al. 2000, Fafchamps \& Minten 2001). In such an environment, market exchange relies on a combination of personalized trust, legal institutions (e.g., to enforce large contracts and to punish thieves), and informal institutions (e.g., reputation sharing within business networks and communities). Whether or not social capital facilitates exchange can then be seen as a test of the strength and reach of formal institutions.

A similar reasoning holds for public goods. Public good delivery is best accomplished when the power of the state to tax and mobilize resources is combined with trust and community 
involvement. The reason is that, without voluntarily accepted discipline, government action is ineffective: taxes do not get paid, rules are not followed, civil servants become corrupt, and free riding reigns. Discipline in turn depends on the perceived legitimacy of government action and the degree of public involvement in the decision-making process. It also depends on identification with the political elites, sense of national urgency, and many other factors which are still poorly understood. The bottom-line, however, is clear: without some form of voluntary acceptance by the public, government efforts to provide public goods are likely to fail. Social capital is thus probably essential for public good delivery. But the form it may take are likely to vary a lot, i.e., from generalized trust in government and formal institutions to interpersonal trust mobilized via clubs and networks.

\subsection{Social Capital and Equity}

We have argued that trust is essential to both economic exchange and public good delivery. We have also argued that clubs and networks can facilitate search and provide an imperfect substitute to generalized trust: in the absence of generalized trust, it may be necessary to rely on clubs and networks. Unlike generalized trust, however, clubs and networks often have distributional consequences that may be quite inequitable. The reason is that, compared to generalized trust, clubs and networks only offer a partial or uneven coverage of society.

Reading some of the literature on social capital, one sometimes has the impression that social capital naturally goes hand in hand with equity (e.g. Uphoff \& Wijayaratna 2000, Robison, Schmid \& Siles 2002). In practice, whether social capital improves or worsens the distribution of welfare depends on the distribution of social capital and the strength of positive and negative externalities.

Consider first the case in which the benefits of social capital principally accrue to those who 
'have it', e.g., to members of a club or network. ${ }^{2}$ They benefit from increased efficiency while non-members benefit less or not at all. As Taylor (2000) and Fafchamps (2002) have shown, the creation of clubs or networks can even penalize non-members. This is because members of a club or network find it easier to deal with each other and, as a result, may stop dealing with non-members. If non-members are richer to start with, building social capital among the poor may improve equity. There is no reason, however, to expect that social capital is in general easier to build among the poor. Social capital takes time and resources. While the poor may have more time, ${ }^{3}$ they have fewer resources. In many cases, richer members of society are richer precisely because they have more social capital. In my work on firms and traders, I have often found that entrepreneurs with better social capital indeed have higher incomes, so that social capital has a unequalizing effect.

In some special cases, it is possible for social capital to increase efficiency but reduce the welfare of members relative to non-members. This arises when externalities are very strong so that members and non-members benefit from the existence of social capital, but only members bear the cost of creating the externality. An example of such a situation is when only some village members voluntarily contribute to the provision of a non-rival public good (Baland \& Platteau 1995). In this case, social capital raises welfare for the village as a whole but the distribution of welfare gains is unequal. Whether this improves or worsens equity in the village depends on whether non-contributors are richer or poorer than contributors. We discuss externalities more in details in the next section.

As the above discussion illustrates, the distributional effects of social capital depend critically on club or network membership. Consider again the case in which social capital benefits those

\footnotetext{
${ }^{2}$ This case does not rule out the presence of positive externalities on non-members, as long as social capital effects are stronger for members.

${ }^{3}$ This may be true of the rural poor, who find little to do. But it need not be true of the urban poor.
} 
who have it. In this case, clubs and networks are least conducive to equity when membership is restricted to a specific group (e.g., men or whites) or when new members are not accepted (e.g., established firms only). Even when new members are accepted without restriction, historical events can shape the composition of clubs for decades whenever entry is slow. In this case, equal opportunity need not be realized because old members have enjoyed the benefits of membership for much longer. By extension, clubs are likely to have undesirable consequences on equity whenever (1) club membership is beneficial to members and (2) entry into the club is not instantaneous. Put differently, clubs raise equity concerns whenever they have real economic benefits.

The creation of clubs may thus reinforce polarization in society between the 'in' group and the 'out' group. Investing in social capital by promoting clubs can thus have serious equity repercussions. This is true even if we ignore the fact that certain clubs may collude to explicitly dominate or exclude others (e.g., Ku-Klux-Klan, mafia) (Gambetta 1993). A similar situation arises with networks because better connected individuals profit from their contacts (Fafchamps \& Minten 2002). Social capital can be used by certain groups to overtake others, generating between-group inequality and political tension. To the extent that between-group inequality itself favors crime and riots and deters investment, promoting social capital by promoting specific groups may, in the long-run, be counterproductive. Of course, at a given point in time, fostering social capital among a specific group may appear as the best way to counteract an existing disadvantage. But once the group is successfully created, the forces we have discussed here kick in and may have unwanted consequences in the long run. 


\section{Estimating returns to social capital}

Having clarified the relationship between social capital and the efficiency of social exchange, we now turn to the statistical analysis of social capital. Borrowing heavily from Durlauf \& Fafchamps (2005), we first ask whether it is possible to uncover social capital effects from the sorts of data available to social scientists. In particular, we discuss the issue of identification, that is, of whether a role for social capital can be distinguished from other social effects that may be present. Then, we revisit the points raised in this section, such as the distinction between individual and aggregate efficiency effects.

The inference questions that we raise here are not specific to economics or to the study of social capital. They apply to inference in general. But the form these inference questions take is shared by many empirical studies of social capital, so that it is useful to discuss them in this context. A growing number of empirical papers on social capital seek to address the various inference issues discussed here. A detailed review of the empirical literature can be found in Durlauf \& Fafchamps (2005). What this reviews shows is that, although progress has been made, much remains to be done. Here we limit ourselves to a brief overview of the main estimation issues.

\subsection{Identification}

The first problem that empirical work on social capital must solve is that of identification. In practice, much work on social capital takes the form of comparing groups or individuals with different levels of social capital. How social capital is measured varies from study to study. But it is common to use membership in a group or network as measure of social capital. For instance, Putnam (2000) uses membership in choirs and business association as well as indicators of socialization. Coleman (1988) compares school performance depending on whether parents 
participate to the management of the school through parent-teacher associations. Granovetter (1995) measures membership in networks. Fafchamps \& Minten (2002) use the number of traders known.

In all these cases, a performance indicator - regional development, school performance, job market performance, or productivity - is compared across groups or individuals with different values of the social capital measure. Formally, let $O_{i}$ be the performance indicator for individual or group $i$ and let $S_{i}$ be its social capital measure. Inference is then organized by testing whether:

$$
E\left[O_{i} \mid S_{i} \text { is high }\right]>E\left[O_{i} \mid S_{i} \text { is low }\right]
$$

In economics, this is typically achieved by regressing $O_{i}$ on $S_{i}$ and a series of controls $Z_{i}$. The same idea can be implemented via a simple $t$-test or, in a case study framework, by compiling evidence from multiple sources without necessarily imposing a formal statistical test.

In all these cases, correct inference requires that, conditional on $Z_{i}$, the two populations those with low $S_{i}$ and those with high $S_{i}$ - be similar in other respects. If this condition is not satisfied, a difference in $O_{i}$ levels between the two populations might be mistakenly interpreted as the result of social capital differences while it is due to other factors correlated with the social capital measure.

There are many possible sources of such omitted variable bias in the study of social capital. Here are a few:

- Leadership: In Section 2 we discussed the role of leadership in harnessing voluntary contributions to a public good. Suppose communities with good leaders have better outcomes. If leaders choose to set up associations to channel their efforts, then communities with an association will have a better outcome even though an association without a leader would 
not deliver equivalent performance. This problem is particularly severe when performance is measured in term of public good delivery. Community leaders often play a crucial role in fostering the creation of social capital - e.g., membership drive - that they can harness for a particular goal. Observing a relationship between social capital and the presence of a public good may be due to the presence of a third, unobserved factor: leadership. The distinction between the two effects is important for policy because good community leaders are rare and leadership is much harder to replicate than groups.

One possible solution to this difficulty is to collect information about potential leaders in all populations, for instance by gathering information about the education level, entrepreneurial experience, and the like. This is difficult to do because the researcher does not know a priori who could be a leader. This means that, in practice, controlling for leadership is extremely cumbersome unless one is willing to assume that the identity of the leader is exogenous - e.g., the village chief.

Another possible solution is to opt for an experimental design and to exogenously change leadership, for instance by introducing an NGO into the community. For the experimental design to be convincing, the treatment effect must be randomly distributed; it cannot be correlated with the social capital measure. Experimental methods are gaining ground in development economics, and we can hope to soon have results of such experiments.

- Institutions: In Section 2, we discussed the role of trust in social exchange and argued that trust can be fostered either by formal institutions or by interpersonal relationships. We made the point that social capital can be a second-best response to the absence of formal institutions: in the absence of a labor exchange, interpersonal relationships facilitate job search. Should formal institutions be more effective, however, relying on interpersonal exchange may become unnecessary (Kranton 1996). This reasoning can be used to explain 
Putnam (2000)'s finding of a widespread decrease in measures of association at a time when the US economy was growing rapidly.

Reliance on interpersonal relationships and networks may thus be seen as a symptom that formal institutions do not work well.

To illustrate how this might impact statistical analysis, suppose we have data on labor markets in different countries and we seek to estimate whether the density of social networks raises the average quality of the match between workers and employers. Suppose for the sake of argument that we have a convincing measure for the average quality of the match. Regressing this measure on the density of social networks is likely to yield incorrect results if the researcher does not control for differences in formal institutions across the countries. For instance, employment offices may play an active match-making role in some countries. ${ }^{4}$ Failing to control for employment offices would underestimate the effect of social capital. In fact, if employment offices channel information more efficiently than interpersonal networks and if these networks arise in response to the absence of employment office, countries with more networks will have less efficient labor markets. ${ }^{5}$

This reasoning can be generalized as follows. Depending on the context, social capital can either be a complement or a substitute for formal institutions, a point that has been investigated empirically for instance by Grootaert \& Narayan (2004). In the example above, social capital is a substitute for formal institutions. To the extent that formal institutions achieve more efficient social exchange than social capital, this may explain

\footnotetext{
${ }^{4}$ In practice, employment offices often play a minor role in matching employers with workers. Perhaps a better comparison is between the US and European markets for academic economists or medical interns: in the US, these markets benefit from a strong coordinating device; in Europe, job matching is uncoordinated and probably less efficient.

${ }^{5}$ The presence of credit reference firms such as Dun and Bradstreet is another example of formal information sharing device that can be partially substituted by informal networks.
} 
Putnam's reverse finding that:

$$
E\left[O_{i} \mid S_{i} \text { is high }\right]<E\left[O_{i} \mid S_{i} \text { is low }\right]
$$

If social capital is a complement, such as a formal business association (e.g. Hendley 1999, Ayouz, Fares \& Tassou 2002), model (3.1) will show a positive association between social capital and performance, without being able to disentangle the respective effects of institutions and social capital. To distinguish the two, one would need observations with and without institutions as well as with and without social capital. In general this is difficult to obtain while keeping the populations similar in other respects. Here too an experimental approach is possible, for instance by phasing in a new institutions over a period of years in a random fashion.

- Group effects: Leadership and institutions are examples of unobserved group effects, i.e., of a factor not observed by the researcher that favors both performance and social capital. There are potentially many other source of group effects, such as commonality of language and religion, co-residence, common interests, and the like. Depending on the context, these factors may have an effect on performance while at the same time be correlated with the social capital measure. In all these cases, inference can be distorted by omitted variable bias. The solution is to collect information about all these possible group effects. As the number of controls grows, so does the size of the sample required for inference purposes.

- Self-selection: This is a concept similar to group effects, but operating at the level of individuals. Say unobserved individual effects cause certain people to self-select into the association or group used as measure of social capital. Further suppose that these individual effects are correlated with individual performance, i.e., that people more likely to 
join the association are also more likely to be high performers. For instance, suppose that smooth-talking is important for business. Further suppose that smooth-talkers, because they enjoy talking, join more association and have more acquaintances. Comparing performance across members and non-members without controlling for self-selection would attribute to social capital - membership in the association - what might in fact be due to unobserved individual effects - smooth-talking.

- Endogeneity: In a world where formal institutions are insufficient and social capital is a substitute for good institutions, the need for social capital will be highest where the need for social exchange is highest. Consequently, individuals are likely to make more effort creating social capital when the potential returns are high. If one uses returns to social exchange as performance measure, one would obtain a positive association between $O_{i}$ and $S_{i}$ due to reverse causation: it is when $O_{i}$ is high that $S_{i}$ is created. A good example of this situation is agricultural trade: large traders may know more traders precisely because they trade with more people. The econometric solution to this problem is to 'instrument' $S_{i}$ by regressing it on factors unaffected by $O_{i}$ (such as parental background, education, and the like). Illustrations of this approach can now be found in numerous papers, notably in many of the papers on social capital produced by the World Bank as well as in Carter \& Maluccio (2003), Maluccio, Haddad \& May (2000), Haddad \& Maluccio (2003), Fafchamps (2003), and Fafchamps \& Minten (2002).

- Reflexivity: as first pointed out by Manski (1993), the empirical study of group externalities is subject to a special king of econometric problem which he called the reflection problem. The difficulty comes from the fact that, if my actions are influenced by the action of others, then my own action influences that of others as well. Consequently regressing my action (or the outcome of my action) on that of others is subject to endogeneity bias. Re- 
flexivity bias is particularly a concern when seeking to document peer effects, for instance by regressing the school performance of a pupil on the test scores of other children in the class. Brock \& Durlauf (2001) have discussed in detail the identification issues raised by reflexivity, with a special emphasis on applications to social capital analysis. More work is necessary in this area.

What the above discussion illustrates is that empirical work on social capital is fraught with danger. While the problems listed above are not specific to social capital, they have often been ignored in early empirical analysis. The purpose of our discussion is to convince the reader that one should be cautious not to make exorbitant claims about social capital without having sought to minimize the various sources of bias listed above.

\subsection{Aggregate versus individual effects}

Durlauf \& Fafchamps (2005) discuss the difficulty of disentangling aggregate and individual effects of social capital. They begin by noting that identifying the effect of social capital from data on groups (e.g., associations, countries) is difficult. Estimating individual returns is easier because the number of observations can be higher, therefore making it easier to control for the various effects discussed in the previous sub-section. Unfortunately, individual returns to social capital often are poor predictors of aggregate effects.

This is best illustrated by focusing attention on two specific processes: fallacy of composition and strong externalities. A fallacy of composition arises whenever social capital pegs individuals against each other. Relative to a situation without social capital, competition for a finite resource or market means that the gains made by those with more social capital lead to losses for those without. Strong externalities can lead to the opposite result in which social gains are larger than those appropriated by the owners of social capital. Once again these problems are not 
specific to social capital - they also arise in the study of human capital, for instance. But they are sufficiently pervasive in social capital analysis to deserve a detailed discussion.

We illustrate how fallacy of composition may affect the estimation of social capital effects with the help of a simple job search example. Suppose there are $M$ job openings and $N$ job seekers, all identical, with $N>M$. Suppose that employer and workers do not know each other and are matched at random. Since $N>M$, all positions are filled and each worker has an equal probability of getting a job $M / N$. Total surplus is the sum of employer and worker surplus. Since all workers are equivalent, total surplus is the same irrespective of which workers get the available jobs.

Next suppose that, thanks to interpersonal connections, a group of workers $C$ hears about the open positions before other workers. Further suppose that $C<M$. Consequently $C$ workers get a job with probability 1 . Other workers get the remaining jobs with probability $\frac{M-C}{N-C}$ which is smaller than $\frac{M}{N}$. Total surplus is unchanged since workers are equivalent. Social capital in this case the existence of a better connected group of workers - thus has no effect on the efficiency of social exchange. But it has important distributional consequences, which can be measured by regressing the probability of obtaining a job on group membership. Doing so in our example would yield a coefficient of $1-\frac{M-C}{N-C}$ on membership in the group even though the net effect of social capital on aggregate welfare is zero. What this example illustrates is that social capital can have private returns even when it has no effect other than distributional on the efficiency of social exchange. Observing private returns to social capital should therefore not be construed as evidence that social capital is socially beneficial. In our example, it is actually discriminatory. The above reasoning can be extended to situations where groups, not individuals, compete with each other (Durlauf \& Fafchamps 2005).

It is also possible that social capital has beneficial effects on social welfare but yields no 
individual returns. This may arise when social capital only has 'external' effects, such as the provision of a non-rival public good. To illustrate this possibility, consider $N$ groups of fisherman tapping the same fishing ground. ${ }^{6}$ Without collective action, there is over-fishing. Suppose that fishing groups with better social capital enforce self-restraint while others do not. Gains from self-restraint are shared among all fishermen, irrespective of whether they have social capital or not. Social capital increases social welfare but fishermen with less social capital have higher profit because they benefit from the self-restraint of others without having to incur the cost. Regressing fish catch on social capital would result in a zero or negative coefficient on social capital even though it has a positive social return for fishermen.

The externality can also be pecuniary, as for instance would obtain if the fishing groups does not share a common fishing ground but sell their fish on the same market: social capital makes collusion to restrict supply possible but all fishermen benefit from higher fish prices. In this case, the effect of social capital can only be ascertained by comparing fishing groups who do not compete with each other, either by accessing the same fishing ground or by selling fish on the same market.

What these examples demonstrate is that individual returns from social capital can be poor indicators of aggregate returns. If social capital enables certain individuals or groups to capture rents at the expense of others, then individual returns to social capital are likely to exceed social returns, and social capital results in unequal outcomes. In contrast, if social capital generates positive externalities not fully appropriated by owners of social capital, individual returns will underestimate social returns. While these considerations complicate empirical analysis, they do not make it impossible, as evidenced by much recent work on social capital.

\footnotetext{
${ }^{6}$ This example is inspired of the work of Platteau \& Seki (2002) on Japanese fishermen.
} 


\section{Conclusions and lessons for policy}

In this paper we have discussed various issues surrounding empirical work on social capital and drawn a number of lessons for empirical work. Starting from a simple conceptual framework, we clarified a number of methodological problems that have plagued the literature. Much work remains to be done and, as the literature begins to mature, the prospects for valuable scientific contributions remain very high.

A proper understanding of the relationship between social, efficiency, development, and equity also has important implications for policy. In the remaining part of this paper, we illustrate these implications by drawing a number of simple lessons from the conceptual framework presented in Section 2. These tentative lessons are only meant to be indicative since the conceptual framework I have proposed has not been formally tested, at least not in its entirety.

Lesson 1: Focusing only on legal institutions and government may not be sufficient to achieve efficiency in exchange and public good provision. This is particularly true in underdeveloped economies where the state is weak and the majority of the population is beyond the reach of courts. Good development policy must pay attention to legal institutions and government as well as trust and leadership.

Lesson 2: Abstracting from cost considerations, promoting generalized trust is in general better than expanding the reach of personalized trust via the promotion of associations (clubs) and networks. This is because generalized trust is more efficient and more equitable (in the Jeffersonian sense of equal opportunity).

Lesson 3: While it is relatively easy to foster the creation of associations and networks, there is no easy way to promote generalized trust in societies where laws have little bite on the majority of firms and economic agents. For this reason, expanding personalized trust is often a more cost-effective way of improving efficiency in developing countries with limited 
administrative capacity to develop formal institutions.

In some cases, it is possible to move towards generalized trust by expanding the reach and inclusiveness of existing associations and networks. One example, discussed in Fafchamps (2002), is the switch from informal to formal information-sharing, such as a credit reference bureau, quality certification agency, or grading system.

Lesson 4: If generalized trust cannot be fostered directly because setting up formal institutions is too costly given the resources of the economy, promoting associations and interpersonal networks may be envisaged provided special care is given to equity issues. Pending further research on these issues, I speculate that equity is best protected if: (1) entry in associations and networks is free and unrestricted; (2) association and network composition are representative of the general population in terms of gender, ethnicity, regional origin, etc; (3) associations and networks do not create entrenched interests that will subsequently slow the replacement of personalized trust with generalized trust.

Lesson 5: Government intervention and community participation are complimentary in the provision of public goods and services. Government can reduce free-riding via taxes and compulsory contributions. Community involvement is required to ensure that the public participates in a disciplined and trustworthy manner to government programs.

Lesson 6: If governments are too weak or disorganized to provide public goods directly, provision can be organized via community-based organizations. In the absence of the state, participation in community-based projects is purely on a voluntary basis. This opens room for adverse selection and free-riding. Effective delivery of public goods on a voluntary basis requires trust and strong leadership. For this reason, successful community-based programs need not be replicable everywhere because of a dearth of strong local leaders.

Lesson 7: Large hierarchical organizations such as Churches, Islamic fraternities, and other 
faith-based organizations can substitute themselves to the state for the provision of public goods. The same is true of international NGOs. Although these organizations do not have the right to raise taxes, they share some of the attributes of the state (large organization with institutional memory, selection of trained leaders, pooling of resources across space). Consequently they are better equipped than small community-based organizations to provide public goods. For this reason, donors dissatisfied with states may choose to work with faith-based organizations and international NGOs for the provision of public goods.

Lesson 8: Working with faith-based organizations and NGOs, however, is fraught with danger because these organizations often have their own social and political agenda (e.g., Hamas). To the extent that faith-based organizations are like clubs with exclusive membership and fairly restrictive entry requirements, they may ultimately get in the way of generalized trust. This was the view of Smith, Jefferson, and Voltaire and the reason why they favored a secular state and sought to weaken the power of the Church.

Lesson 9: Social capital must not become a new mantra. It must not be used to justify pouring resources into community development efforts that have a low chance of success and low replicability (because of the dependence on unpredictable local leadership). Social capital is not an easy or cheap replacement for an effective state. If the state is broken, why not fix it. Investing in social capital should be seen as a complement to investing in government capacity. The two cannot and should not be separated.

\section{References}

Akerlof, George A. \& Rachel E. Kranton. 2000. "Economics and Identity." Quarterly Journal of Economics 115(3):715-53.

Ayouz, M. K., M. Fares \& Z. Tassou. 2002. "Association des commer cants, capital social et 
compétitivité : Tests économétriques sur les données des commer cants des produits vivriers du Bénin." (mimeograph).

Bala, Venkatesh \& Sanjeev Goyal. 2000. "A Non-Cooperative Model of Network Formation." Econometrica 68(5):1181-1229.

Baland, Jean-Marie \& Jean-Philippe Platteau. 1995. Halting Degradation of Natural Resources: Is There a Role for Rural Communities? Oxford, England: Food and Agriculture Organization; Clarendon Press.

Barr, Abigail. 2002a. Familiarity and Trust: An Experimental Investigation. Oxford: CSAE, Oxford University.

Barr, Abigail. 2002b. "Risk Pooling and Limited Commitment: An Experimental Approach." (mimeograph).

Barr, Abigail. 2002c. "Cooperation and Shame." (mimeograph).

Bebbington, Anthony, Scott Guggenheim, Elizabeth Olson \& Michael Woolcock. 2004. "Exploring Social Capital Debates at the World Bank." Journal of Development Studies 40(5):3364.

Becker, Gary S. 1968. "Crime and Punishment: An Economic Approach." Journal of Political Economy 76:169-217.

Bernstein, Lisa. 1992. "Opting Out of the Legal System: Extralegal Contractual Relations in the Diamond Industry." Journal of Legal Studies XXI:115-157.

Bernstein, Lisa. 1996. "Merchant Law in a Merchant Court: Rethinking the Code's Search for Immanent Business Norms." University of Pennsylvania Law Review 144(5):1765-1821. 
Bigombe, Betty, Paul Collier \& Nicholas Sambanis. 2000. "Policies for Building Post-Conflict Peace." Journal of African Economies 9(3):323-48.

Bigsten, Arne, Paul Collier, Stefan Dercon, Marcel Fafchamps, Bernard Gauthier, Jan Willem Gunning, Anders Isaksson, Abena Oduro, Remco Oostendorp, Cathy Patillo, Mans Soderbom, Francis Teal \& Albert Zeufack. 2000. "Contract Flexibility and Dispute Resolution in African Manufacturing." Journal of Development Studies 36(4):1-37.

Bloch, F., Garance Genicot \& Debraj Ray. 2004. "Social Networks and Informal Insurance." (mimeograph).

Brock, William A. \& Steven N. Durlauf. 2001. Interactions Based Models. In Handbook of Econometrics. Vol. 5 Amsterdam: North Holland pp. 3297-3380.

Carter, Michael R. \& John Maluccio. 2003. "Social Capital and Coping with Economic Shocks: An Analysis of Stunting of South African Children." World Development 31(7):1147-63.

Coleman, James S. 1988. "Social Capital in the Creation of Human Capital." Amer. J. Sociol. 94(Supplement):S95-S120.

Collier, Paul \& Anke Hoeffler. 2002. Greed and Grievances in Civil War. Oxford: Center for the Study of African Economies, Oxford University. WPS/2002-01.

Dasgupta, Partha \& Ismail Serageldin. 2000. Social Capital: A Multifaceted Perspective. Washington DC: The World Bank.

de Soto, Hernando. 1989. The Other Path: The Invisible Revolution in the Third World. New York: Harper and Row. (translated by June Abbott).

Durlauf, Steven \& Marcel Fafchamps. 2005. Social Capital. In Handbook of Economic Growth. New York: Wiley. (forthcoming). 
Fafchamps, Marcel. 2002. Spontaneous Market Emergence. In Topics in Theoretical Economics. Vol. 2(1), Article 2 Berkeley Electronic Press at www.bepress.com,.

Fafchamps, Marcel \& Bart Minten. 1999. "Relationships and Traders in Madagascar." Journal of Development Studies 35(6):1-35.

Fafchamps, Marcel \& Bart Minten. 2002. "Returns to Social Network Capital Among Traders." Oxford Economic Papers 54:173-206.

Fafchamps, Marcel. 2003. Ethnicity and Networks in African Trade. In Contributions to Economic Analysis and Policy. Vol. 2(1) Berkeley Electronic Press at www.bepress.com p. article 14 .

Fafchamps, Marcel. 2004. Market Institutions in Sub-Saharan Africa. Cambridge, Mass.: MIT Press.

Fafchamps, Marcel \& Bart Minten. 2001. "Property Rights in a Flea Market Economy." Economic Development and Cultural Change 49(2):229-268.

Gambetta, Diego. 1993. The Sicilian Mafia: The Business of Private Protection. Cambridge, Mass.: Harvard University Press.

Goyal, Sanjeev, Marco van der Leij \& Jose Luis Moraga-Gonzalez. 2004. "Economics: An Emerging Small World?" (mimeograph).

Granovetter, Mark S. 1995. Getting a Job: A Study of Contacts and Carreers. Chicago: University of Chicago Press. 2nd edition.

Grootaert, Christiaan \& Deepa Narayan. 2004. "Local Institutions, Poverty and Household Welfare in Bolivia." World Development 32(7):1179-98. 
Grootaert, Christiaan \& Thierry van Bastelaer. 2002a. The Role of Social Capital in Development: An Empirical Assessment. Cambridge: Cambridge University Press.

Grootaert, Christiaan \& Thierry van Bastelaer. 2002b. Understanding and Measuring Social Capital: A Multidisciplinary Tool for Practitioners. Washington DC: World Bank. Direction in Development series.

Haddad, Lawrence \& John Maluccio. 2003. "Trust, Membership in Groups, and Household Welfare: Evidence from KwaZulu-Natal, South Africa." Economic Development and Cultural Change 51(3):573-601.

Hayek, F. A. 1945. "The Use of Knowledge in Society." Amer. Econ. Rev. 35(4):519-530.

Hendley, Kathryn. 1999. "Beyond the Tip of the Iceberg: Business Disputes in Russia." (mimeograph).

Keefer, Philip \& Stephen Knack. 1997. "Why Don’t Poor Countries Catch Up? A Cross-National Test of Institutional Explanation." Economic Enquiry 35(3):590-602.

Kranton, Rachel \& Deborah Minehart. 2001. "A Theory of Buyer-Seller Networks." American Economic Review 91(3):485-508.

Kranton, Rachel E. 1996. "Reciprocal Exchange: A Self-Sustaining System." Amer. Econ. Rev. $86(4): 830-851$.

Maluccio, John, Lawrence Haddad \& Julian May. 2000. "Social Capital and Household Welfare in South Africa, 1993-98." Journal of Development Studies 36(6):54-81.

Manski, Charles F. 1993. "Identification of Endogenous Social Effects: The Reflection Problem." Review of Economic Studies 60:531-42. 
Narayan, Deepa \& Lant Pritchett. 1999. "Cents and Sociability: Household Income and Social Capital in Rural Tanzania." Economic Development and Cultural Change 47(4):871-897.

North, Douglas. 2001. Comments. In Communities and Markets in Economic Development. Oxford: Masahiko Aoki and Yujiro Hayami (eds.), Oxford University Press pp. 403-8.

North, Douglas C. 1973. The Rise of the Western World. Cambridge: Cambridge U.P.

Platteau, Jean-Philippe. 1994. "Behind the Market Stage Where Real Societies Exist: Part II The Role of Moral Norms." J. Development Studies 30(4):753-815.

Platteau, Jean-Philippe \& Erika Seki. 2002. Community Arrangements to Overcome Market Failure: Pooling Groups in Japanese Fisheries. In Communities and Markets in Economic Development. Oxford: Masahiko Aoki and Yujiro Hayami (eds.), Oxford University Press.

Putnam, Robert D. 2000. Bowling Alone. New York: Simon and Schuster.

Putnam, Robert D., Robert Leonardi \& Raffaella Y. Nanetti. 1993. Making Democracy Work: Civic Institutions in Modern Italy. Princeton: Princeton University Press.

Robison, Lindon J., A. Allan Schmid \& Marcelo E. Siles. 2002. "Is Social Capital Really Capital?" Review of Social Economy 60(1):1-21.

Rose, Richard. 2000a. Getting Things Done in an Antimodern Society: Social Capital Networks in Russia. In Social Capital: A Multifaceted Perspective. Washington DC: P. Dasgupta and I. Serageldin (eds.), The World Bank pp. 147-71.

Rose, Richard. 2000b. "Uses of Social Capital in Russia: Modern, Pre-modern, and Antimodern." Post-Soviet Affairs 16(1):33-57.

Tadelis, Steven. 1999. "What's in a Name? Reputation as a Tradable Asset." American Economic Review 89(3):548-563. 
Taylor, Curtis R. 2000. "The Old-Boy Network and the Young-Gun Effect." International Economic Review 41(4):871-91.

Uphoff, Norman \& C.M. Wijayaratna. 2000. "Demonstrated Benefits from Social Capital: The Productivity of Farmers Organizations in Gal Oya, Sri Lanka." World Development 28(11):1875-90.

Woolcock, Michael \& Deepa Narayan. 2000. "Social Capital: Implications for Development Theory, Research, and Policy." World Bank Research Observer 15(2):225-49. 